\title{
A Research of Officials Recruitment Regime in The Early Le Dynasty
}

\author{
Author: Dr. Nguyen Thi Thu Hoa \\ Faculty of Politics and Administration, Ho Chi Minh National University, \\ Vietnam
}

Email: nguyenhoadhnvhcm@gmail.com

DOI: 10.26821/IJSRC.9.9.2021.9921

\begin{abstract}
It has been proved in Vietnamese history that the early period of the Le dynasty (1428-1527) was the most brilliant imperial period with outstanding achievements in the national construction and development. It is considered the golden period of the development of feudalism of Vietnam.The main purpose of this study is to empirically test theofficials recruitment regime in the early Le dynasty in Vietnam. The author collected secondary data from previous studies. The results of the research show that the mode of selection of mandarins in the early Le dynasty, including (i) Appointment by heredity (recruitment of mandarins from among children of the aristocracy); (ii) Nomination regime; (iii) Recruitment through examinations; and (iv) Some other selection systems.Based on the findings, some conclusions are given.
\end{abstract}

Keywords: recruitment regime, Le dynasty, Ordinance of nomination, Confucian court examination system

JEL codes: B10, J53, M12, M54, O15

\section{INTRODUCTION}

It has been proved in Vietnamese history that the early period of the Le dynasty (1428-1527) was the most brilliant imperial period with outstanding achievements in the national construction and development. It is considered the golden period of the development of feudalism of Vietnam. During those 100 years, Dai Viet state had become a country with a powerful position in Southeast Asia in all fields of economy, politics, culture and society. To achieve that position, the early Le dynasty had focused on building a strong centralized monarchy state and implementing social management by law. The dynasty also associated the job of building and strengthening political institutions according to Confucian ideology with the implementation of the mandarin regime as a central task. Many guidelines, measures, regulations and rules related to training, selection, employment, promotion, punishment, salary, etc. of mandarins, were promulgated by the kings of the Le dynasty in order to manage a team of mandarins structurally and effectively. The Management Committee of the early Le dynasty really contributed to creating an organized administrative order and a solid mandarin system, becoming the "main pillar" of the country and the brilliant role model for the following dynasties. Its values are always the basis, foundation, and valuable lessons for today's generation to learn, inherit and develop. With these achievements, the early Le dynasty mandarin regime definitely deserves being studied and inherent by today's generations. This study presents and analyzes the mode of selection of mandarins in the early Le 
Volume 9 Issue 9 September 2021

dynasty, including (i) Appointment by heredity (recruitment of mandarins from among children of the aristocracy); (ii) Nomination regime; (iii) Recruitment through examinations; and (iv) Some other selection systems.

\section{THEORETICAL BACKGROUND AND LITERATURE REVIEW}

Previous studies have focused on the organizational model of administrative apparatus from the central to local levels of the Le dynasty, discussing the structures of administrative apparatus under the reign of King LeThanh. A typical example is Le Kim Ngan's study (1963), in which all the prominent officials titles under the reign of King LeThanh Tong were presented, and subsequently evaluated that mandarin system along with its duties, functions, and management of officials' capacity and service morale. However, this study stopped at analysing administrative apparatus at central level; whereas administrative apparatus and at local level was not mentioned. Therefore, no report was made from research into administrative apparatus at local level.

Scientific conference on the virtue and life of King LeThanh Tong (1997) contributed new observations and interpretations of the life and legacy of King LeThanh Tong through several subjects, including: The title of commune chief under the reign of King LeThanh Tong; reforms of the mandarin system at local level under the reign of King LeThanh Tong; Observations of changes in administrative matters and local authority organizing under the reign of King LeThanh Tong, etc. These articles mentioned several areas in which King LeThanh Tong wanted to implement reforms during his reign, prominently administrative apparatus. The seminar's report also gave new insights into the life of LeThanh Tong - a king of wisdom and pragmatism.

Researches by Minh Dat (2006) and Truong HuuQuynh (1992) on organization of apparatus of the early Le Dynasty are valuable work of research for reference.

The studies above imply that the system of administrative agencies under the early Le Dynasty was efficiently organized, with specific functions and assignments, without overlapping on those of others. It would not be over-exaggerating to conclude that the advantages of LeThanh Tong's post-reform administrative system are the reason why it was considered the standard/system for later dynasties.

\section{METHODOLOGY}

This study uses qualitative research methods.

The author collected previous studies.

In addition, the author used techniques of synthesis, analysis, comparison to evaluate the mode of selection of mandarins in the early Le dynasty.

Qualitative research methods orientated and refined the research results of previous studies; from there, this study inherited and applied.

\section{RESEARCH RESULTS}

\subsection{Male hereditary succession (family's blessings)}

Hereditary succession or family's blessings was the earliest form of electing bureaucrat scholars in the history of Vietnam, and became a political custom in which the power and privileges were passed along the succession line. "Am” in Sino-Vietnamese means grace and blessings inheriting from predecessors (Hoang Phe, 2000). "Tap am - family's blessings" is a kind of the king's favor to the descendents of mandarins who have merits; 
Volume 9 Issue 9 September 2021

after one's demise, it would rely on the mandarin's title and rank to offer the children with privileges in 3 levels: "am sinh-education and training privilege", "am thu-position inheritance privilege", "am ton-privilege for grandchildren", so that the descendants have the opportunity for training to be an bureaucrats, usually with a certain term of time"(Pham Van Hao, 2008). In accordance with this custom, the male descendants, thanks to the grace of their predecessors, would be appointed to a certain official position. If the family doesn't have a male descendant, they will be allowed to adopt a male relative to inherit the privileges of Family blessings.

This ordinance promptly resolved the temporary shortage of mandarins, especially after fierce wars when formal training and education for new mandarin was not affordable. "Tap am" was also advantageous for the following reasons:

Firstly, families of officials generally had a better economic background than ordinary families. As a result, they could afford high-quality teachers for mentoring or send their children to private schools with famous teachers and to public state schools (QuocTuGiamSchool - the Imperial Academy, for example). This was a chance for their children to learn together with students of noble origins or excellent Confucian students.

Secondly, as young children of mandarins, they were introduced to and familiar with the environment and manners at Yamen(the office or residence of a public official). As young adults, they were allowed to work as assistants at their father's and grandfather's public office in public matters. Therefore, they could learn valuable administrative skills, governance principles and accumulate experience.

Thirdly, most of the mandarins and generals at that time were very loyal, conscientious, and gracious officials of the court, who had tremendous contributions. As they were granted with such 'privileges and tribute', the officials would devote themselves wholeheartedly, for the sake of the family's benefits and traditions as well as their own honor. In addition, the children who inherited “Tap am”privilegeswould be facilitated to train and strive to become good officials who could earn glory for their families and become the role-model for their descendants. This helped develop an educational model within the family that followed the motto "To lead a country, one must first lead his family" (a person must learn to build a good family before he can become a good official).

The biggest limitation to this system is that some of the inherited mandarins did not undergo any form of examination or test, were not properly trained or equipped with sufficient amounts of basic knowledge and skills, or their competencies were not fully assessed, etc. This made them vulnerable to commit acts of corruption and venality, and turned their career paths as a mandarin into a means of self-interest.

In order to promote the positive side and minimize the negatives of this "Tap am - family blessings" system, the law of the early Le dynasty had many strict regulations on conditions and procedures for a person to inherit "Tap am" to become a mandarin. Article 50, Chapter Vi Che(Administrative crime code), the QuocTrieuhinhluat National Criminal Code stipulated that if the order of first and second son is misjudged during the assessment for "Tap am", the responsible court's bureaucrats and appraisal agents will be sentenced to corporal punishment, penal labour or exile; Article 118 stipulated punishments for mandarins who adopt other people's grandchildren to be their own grandchildren, in order that they could inherit the "Tap am" privileges; Article 14. Chapter Tra(dishonesty and deceit crime code) stipulated that those who counterfeit other's "Tap am" certification to cheat their ways to be a mandarin will be sentenced to penal labour and corporal punishment and fined 50 quanLe Dynasty’s currency (National Criminal Code, 1991). Besides, the early Le Dynasty also introduced a rule of “am sung”. "Am sung” was prioritised for descendants of officials and agents who had meritorious services to 
Volume 9 Issue 9 September 2021

be recruited for certain positions, or to receive certain benefits (to inherit "am sinh" - be admitted to QuocTuGiam after an examination. Every 3 years,Tuhuan(counselors and teachers here) had to make full reports about their students' merits, conduct and qualifications and then transferred to Bo Le(Ministry of Rites) for assessments. Students of merit would be appointed to be mandarin. In addition, the criteria forrecruitment was very specific: "Resident students at The Imperial Academy, age over 30. Those who merited to be recruited as new mandarin would be reserved and summoned in times of need" (Truong HuuQuynh, 1992)

In conclusion, hereditary succession "Tap am - family's blessings" of the Le dynasty filled up vacancies in the mandarin system after the war. In addition, it reflected the recognition of the dynasty for the merits of the mandarins, complying with "respect the meritorious" regulation. At the same time, in order to ensure the legitimacy and purpose of the regime, the law strictly dealt with arbitrary and illegal acts. Thus, the family's blessings came into play and contributed to supporting other mandarin selection customs.

\subsection{Ordinance of nomination}

There are two types of nominations: (i) self-nomination and (ii) recommendation. Self-nomination takes place when a candidate possessing required competencies and virtue promotes himself for the vacancy. The preference of the court was someone who was talented and virtuous, regardless of their social status. Recommendation (or bao $\mathrm{cu}$ ) refers to the state of being nominated by a prestigious mandarin who must take responsibility for ensuring the virtue of the candidate in front of the court.

According to this custom, talented and virtuous candidates desiring to shoulder nationally utmost responsibilities were appointed without coming under scrutiny. This was of significant importance to the task of promptly overcoming the shortage of officials in the government apparatus, especially at the early stage of the dynasty, or during periods of social volatility, which was not conducive to the election. With the assurance of prestige and responsibility of the nominator, the nominated must be those having genuine talent, virtue and experience as well as practical ability to meet the requirements of the tasks set out.

In 1482, LeThanh Tong ordered the appointment of Thuaty- Administration Commissioners that: "Given how significant Thua Tyare, they must meet the people's expectation for them. From now on, should there be any vacancies in this mandarin system, the Ministry of Personnel must report them to the King and delegate the issue to courtiers. Similar to the custom of recommending Military and Inspectorate commanders, both internal and external mandarins will be considered, and those who merit will be appointed " (PhanHuy Chu, 1961).

At the early stage of the Le dynasty, the organization of the state apparatus was still very simple. There were many talented people in the country, but for different reasons, they did not devote themselves to the court. Therefore, in 1429, one year after the enthronement, Le Thai Toissued a decree to recruit men of talent and righteousness, edicting that: "Prosperity and wealth are all roots from services of civil servants; May there be a man of talent and righteousness, he must be nominated. A wise king must take it as first priority, etc. Carrying an enormous burden of the country's matter, I have a concern that the brightest men may never be found, such great concern that follows me into my sleep. Thus, each of military officers, civil mandarins and third-rankupwards courtiers hereby must comply with my command to recommend a nominee, no matter if he is in the court or from the farm, mandarin or not. if there is an expert on literature and martial arts, a man of knowledge and leadership, bring him to me, I will recruit him in respect of his talent". The king also said, "There are numerous talented people, as much as ways to find them. There are contributing men but at low positions and those dwelling either in the countryside or in the army. If you don't propose your talents, how am I supposed to 
Volume 9 Issue 9 September 2021

know? From now on, those who desire to follow my lead, I permit you to nominate your own self... Once this royal proclamation comes into effect, I expect all mandarins to enthusiastically and wholeheartedly propose. And the wise in remoteness should not be ashamed of being utilized, don't worry me with this shortage of talented people" (PhanTrongBau, 1994).

In 1477, LeThanh Tong issued a decree specifying that mandarins in the court must only nominate someone with an upright character to be a district mandarin. In 1482, King LeThanh Tong ruled about the appointment of Thuaty- Administration Commissioners in provinces: "Given how significant Thua Ty at provinces are, they must meet the people's expectation for them. From now on, the Ministry of Personnel must report any vacancy to the King and delegate the issue to courtiers. Military and Inspectorate commanders would appoint both internal and external officials, whoever suitable to hold the position will be suggested to the Ministry of Personnel"(NgoSy Lien, 1992)

As this recruitment method was prone to generate fraudulence from the nominees and the nominators, the law strictly regulated the standards for both nominees and nominators. KingLe Thai To assigned third-rankedupward mandarins to promote virtuous and talented people for the court. "A mandarin would be kindly rewarded for promoting talents. That is still as rightful as how it was in the past. If his nominees can prove their values, he will be promoted 2 ranks. Or if he can find a man of extraordinary talent and virtue, he will certainly all be generously rewarded." Meanwhile, the King stipulated the responsibilities of nominators; severe punishments for nominating people who are not qualified,strictly obeying the law. "At that time, as the election was done properly, together with severe punishments, no one dared to commit any act of fraudulence, only the worthy were nominated; thus, worthy people were appointed to their worthy positions" (PhanHuy Chu, 1961). Article 714 of the National Criminal Code provided: "Those who failed the task of genuinely nominating would be demoted or punished according to the law; the punishment would be considered two levels more severe if there is any sign of relative partiality or bribery" (National Criminal Code, 1991). The case of Dao Bao was a typical testament to this. Under the reign of King LeThanh Tong, in 1467, he nominated Han Dinh and Nguyen Duc, who were proved to be not worthy enough. When this misdeed came to light, Dao Bao was at first sentenced to death, but then he was spared and sentenced to penal labour on the farm. Han Dinh and Nguyen Duc were dismissed and sent back to their hometown. In the eighth QuangThuan year (1467), LuongNhu Hoc was given a custodial sentence by the King for recommending an unqualified nominee named QuyHuyen, who was dismissed after that. In the light of this strict reward-punishment regulation, the practice of electoral bribery was confined and controlled during the Le dynasty.

In general, this custom of nomination was the reason why the Le dynasty made the most use of talented people who were able to participate in the government without going through complicated procedures. Perhaps the custom had laid a solid foundation for the general prosperity of the Le dynasty.

\subsection{Confucian court examination system}

The purpose of selecting mandarins of the Le dynasty is cogently expressed according to an opinion: "To see the talented, choosing intellectuals is a prerequisite, in which examinations have to be ranked the most important factor to pick ones" (NgoSy Lien, 1992). During the Le dynasty, confucian court examination was mostly held annually (as an usual procedure). Le Thai Tong wanted to assess the combination of three elements of a genius, which were: learning from books, schools; serious attitude for examination and practical political participation. These three aspects blended to promote a society that values education, culture, and personal talent training. An 
Volume 9 Issue 9 September 2021

educated mandarin will certainly know how to govern the people, creating a high level of management and unity.

During the reign of LeThanh Tong, with the aim of recruiting a new class of mandarins of Confucianism through examinations, he implemented drastic reforms in the selection of mandarins. He wanted to replace the aristocratic mandarin class (former mandarins) with the Confucian intellectual bureaucracy, thereby limiting the formation and development of mandarins under nepotism but create a team of mandarins with absolute loyalty and talents to shoulder the task of governing the country.

LeThanh Tong told the mandarins: "You and I have sworn to heaven and earth to appreciate gentlemenand ignore petty people; to devote day and night, don't you ever forget" (NgoSy Lien, 1992).

\section{Exam organization}

Since Le Thai Tong ordered the mandarins to revise the examination regulations, the Confucian examinations became a routine and an important source to provide human resources and talents for the state apparatus. As analyzed above, in order to have positions of authority in the mandarin class, in principle, men must study and pass the examinations. These were mandatory requirements for mandarins from district level and above. The early period of the Later Le dynasty sequentially promulgated the rules and principles on examinations, which became the regime of the country. There were three main exams in the dynasty's education system, namely Huong, Hoi and Dinh. For 100 years, with the principle "education for all without discrimination", the early period of the Later Le dynasty built a mandarin system based on imperial examinations that was far superior to the previous and subsequent feudal periods, both in quality and quantity. In fact, this period organized 31 exams (with 1,007 doctors) out of a total of 182 exams (with 2,898 doctors) of the entire feudal history of Vietnam. Compared to the general rate, the number of Dinh exams Keld by the early period of the Later Le was insignificant (accounting for 17\%), but the number of qualified doctors took up nearly $35 \%$.

In addition to the doctoral examinations as mentioned above, the early period of the Later Le dynasty also had other exams such as Minh Kinh, HoanhTu, LaiVien. The organization of the Lai Vien examinations was exclusive to the state and assigned to the Ministry of Rites to propose to the king who made the final decision. Typically, to be qualified as clerks at yamens, candidates had to pass the Thutoan exam (a series of examinations testing classic literature and mathematics). When it comes to recruiting clerical positions, the Ministry of Personnel must first check whether candidates passed the Thutoan exam. Those who passed this exam were called Lai su co xuat than (qualified clerk or secretary position). They were also entitled to more privileges than those who did not have a Thutoan exam's degree. In recruitment process, people who had the Thutoan exam's degree were initially entitled to the position ofThulai(paperwork and mail keeper in yamens) for 3 years before being promoted to Datlai (also the paperwork keeper but one rank higher than Thu lai). After another 3 years, if there were no defects, they would then be promoted to DoLai (mandarin in a district).

In the early stages of their career, those who did not have the ThuToan exam's degree held the position of Thong lai (paperwork and official dispatch carrier) for 9 years before being promoted to delai (chronicler in districts). After 3 years, if considered worthy, they would be promoted to dolai. Being appointed to work in yamens were often qualified clerks.

The candidates of the Hoi, the Huong exams were also appointed Thuoclai. History said that: In the 8th Year of QuangThuan (1467), Thanh Tong decided that those who took the Hoi, the Huong exams would be appointed to 
Volume 9 Issue 9 September 2021

be Thuoclai in yamens. Preceptors were assessed so that whoever won first place in the Hoi exam was appointed Kinh lich. Students were examined by the Ministry of Personnel to be appointed fifth rank district mandarins and Thuoclai in yamens were examined to be appointed preceptors in provincial offices.

\section{Regulation on selection activities through examinations}

Firstly, severely punish exams violators

In order to administer serious examinations, to find talents and eliminate acts of cheating in the exams (bribery or harassment), examinations under the early period of the Later Le dynasty were strictly organized. The National Criminal Code of the Le dynasty ruled and strictly punished any form of cheating while taking exams or the act of hiring others to take the tests. Invigilators must not allow students to bring books into the exam school (National Criminal Code, 1991). The law also prohibited the copying and swapping of candidates' papers. Objectivity in the selection of mandarins on the one hand motivated everyone in the society to study, as well as contributed to the elimination of existing conditions of corruption and abuse of invigilation or marking process to harass students. The Le Dynasty also applied Hoi ty(the Rule of avoidance) strictly in the Huong and Hoi exams. Those who had a personal relationship with the candidate would not be allowed to be judges to ensure objectivity in evaluating test results. Examiners had to avoid meeting contestants whom they knew. If this rule is violated,they will be "fined 50 lashes, demoted one rank". If violators wereDi Phong mandarins (responsible for sealing the exam books in the Dinh exam to hand to the king), dang luc mandarins (responsible for copying the candidate's paper so that the examiners mark without acknowledging the candidate's handwriting), they would be punished with "80 strokes" (National Criminal Code, 1991).

The downside of utilising Confucian court examination to select talents is that induces the likelihood of resorting to bribery to falsify data to favour the candidates. The King usually assigned the management of selection, invigilation and examination to senior officials. Taking advantage of their responsibilities, those mandarins could alter information, collude with either associates or bribe-givers to create false results and abet them in impersonation during the tests. There were a number of incidents recorded in Dai Viet sukytoanthu(Vietnamese Book of History). For instance, Le Sat was executed by King LeNhan Tong due to committing bribery in exam; in 1447, King LeNhan Tong also removed LeCanhXuoc from the Privy Council as he was caught receiving 20 quanto help a candidate be elected in the government officials system; in 1448, Trinh KhacPhuc, a mandarin in Ministry of Justice, accepted money to help DuyKhiem gain admission to the Imperial Academy, ect.

To sum up, bright sides of the initial phase of applying examinations into mandarin system selection were inevitably accompanied by its disadvantages, namely degenerate officials assisting litigants in cheating and impersonating. Nonetheless, thanks to various strict regulations, the Later Le Dynasty was able to restrict these limitations.

Secondly, using the Huong exam's commitment to guarantee the identity and morality of the candidates.

According to it, the local community needed to validate the status as well as morals of the Huong exam's contestants in their three-generation resume. They were required to have clear backgrounds and virtues regardless of social status. It was the mandarins in committees and districts that were responsible for the preliminaries. They would make lists, review backgrounds; accordingly, those who did not meet the standards (if one was from an actors and singers family (whose occupations were then deemed immoral); or he was rebels 
Volume 9 Issue 9 September 2021

or was sentenced to lacking filial piety, being incestuous or disloyal, he and his offsprings could not compete) were not qualified to enrol in the test notwithstanding the high qualifications.

Not only did that statute help the Later Le Dynasty attract a great number of geniuses but it also strictly guarantees to select the appointees who were adept, honourable, attentive to civilians' lives and not corrupted by personal benefits (Quocsuquantrieu Nguyen, 1998). After the commitment, contestants must sit for khaohach or am ta tests so that only the fully accomplished ones could participate in the real exams. Moreover, the Court distributed the number of candidates among local communes with a view to ensuring equity in quality and quantity. As for the candidates who were already clerks in the government agencies, should they want to compete, they also have to register, pass the preliminary test and return to their native villages.

On the contrary, unless qualified Confucian students enrolled or joined the test regardless of rationales, they would be charged with crime, which was similarly documented in the official history. Those who were in parental mourning needed to sign up in their $p h u$, in case their absences were detected, they would be forced to enlist as soldiers. Whoever arbitrarily took exams outside the exam centres or had impersonators write exams, he would be considered criminals and permanently debarred from taking examinations and being eligible for admission as well. If the village chief was caught supporting candidates to cheat, he would have to serve as soldiers of the third rank in phu. Apparently, the contestants' qualifications were rigorously selected according to educational backgrounds and contemporary moral standards.

Thirdly, invigilating the examinations.

The Ministry of Personnel and Imperial Academy played a crucial role in training and electing gifted individuals by civil services examinations. Yet these organizations were accountable to the King and closely supervised by the Ministry of Rites and Lai Khoain order to ensure equality, objectivity and eschew negativity. The King entrusted Lai Khoawith the responsibility for invigilation and selection. Supposing that he noticed any act of cheatings, he would instantly interrogate the Ministry of Personnel then report to the King and simultaneously consult with him on proposing plausible sofution

Additionally, the Le Emperors paid special attention to the exams' tasks. When it came to content and style, the questions were constantly changed in terms of contents and styles so that contestants' creativity was strongly stimulated. For example, in the HongDuc dynastic year (1470-1497), there were no constraints of chapters and historical phases on the KinhNghia test, so candidates ought to have excellent command of canonical Confucian texts. The question categories might be Tuluc, poem, phu, ancient history, issues lying outside the classic books, contemporary politics or the policies implemented by the former kings.

Fourthly, the customs of quyvinhbai to "Triumphal Return" and stone stelaes.

In accordance withDai Viet sukytoanthu, the customs of stone stelaes and "Triumphal Return" were promulgated by King LeThanh Tong in 1484. Specifically, the new laureate was given lavish banquets, clothing, scarves and belts, then was accompanied by servants on his triumphal return; moreover, his name was engraved on stelae as well. The public in the laureate's province, district, committee and village would proudly welcome him back home with flags, parasols, drums and gongs. If he was married, his wife would be carried on a hammock, following right behind him. Besides, there would be other ones lifting his parents and teachers so that the laudreate could express his gratitude to them after praying to his ancestors in the family's church and communal house. "Triumphal Return" was not only a privilege for the new laudreate, his family and acquaintances but also a precious chance for him to pay his utmost respect for his ancestors, parents and 
Volume 9 Issue 9 September 2021

teachers, which was akin to the Vietnamese custom of appreciating their considerable merits.

Therefore, the selection of mandarins by means of examination was the main method of selection, which, in comparison to nomination, recommendation and family's blessings, had the most advantages. Most of the central and local state officials of the Early Le dynasty were selected through examinations. The Early Le dynasty performed the selection of mandarin through examination strictly, seriously, organizedly and scientifically.

\subsection{Some other ordinances}

\section{Election}

The Electoral method is applied to the selection of the commune chief position. The method of electing a commune chief is newer compared to previous dynasties. In the Ly and Tran dynasty, the head of the commune was the communal mandarin assigned by the central court. Under the reign of King LeThanh Tong, the commune mandarin position was changed to commune chief, who had to be elected by the people of that commune. The election of commune chiefs is based on standards set by the state.

The person to be elected a commune chief had to come from Confucian background, be a student or a bachelor, have good conduct, must be over 30 years old, and devoted diligently. The elected commune chief must also be recognized by the central court. The commune chief is not only the representative for the voice of the commune's people but also for the court to collect tax collection and inspect the population. Election shows a broad democratic approach of the grassroots level of the contemporary administrative apparatus, being the testimonials to LeThanh Tong's vision with his understanding of the characteristics of the economic, social, and cultural structure of communes. Electing a commune chief is to promote the power of the commune's people and harness it to implement the state's policy.

\section{Monetary exchange}

In addition to the above selection methods, in the early years of his reign, LeThanh Tong also permitted the act of buying some titles. The available titles are only non-crucial ones. This method did not greatly influence the quality of the mandarin regime of the early Le dynasty. Moreover, the recruitment through buying titles in the early Le dynasty also has its own benefits as follows: "In 1460, the king issued an edict for all people of all classes in the country. Those who own lots of rice and are willing to offer, can come to the bureau to report, depending on the amount of rice, the corresponding title will be granted. For 200 dan (1 dan equals $0.6 \mathrm{~kg}$ ) of rice offered he will be granted a position of chanh that pham (chief seventh rank), for 150 dan he will be granted a position of tong that pham(vice seventh rank), for 100 danhewill be granted a position of tong bat pham (vice eighth rank) and their children would be exempted from military services. And for 70 dan he will be rewarded $1 \mathrm{tu}$ and have poll tax exempted."

\section{Condescending recruitment (Tientrieu)}

This type of ordinance was applied to students who scored well in multiple exams, but failed to earn doctorate titles. If it is either that his family is prestigious, or his relative is an official, or he could prove his talent, etc, he will be appointed similarly to a doctor, after his talent and virtues have been guaranteed by an official in the Court. This is an uncommon method of recruitment, but was approved during the Early Le Dynasty.

To summarize, these different forms of electing and recruiting mandarin made it clear that mandarins under the Early Le Dynasty were recruited in a variety of methods, including new methods, such as public election or condescending recruitment, etc. There were also strict and sophisticated regulations to supervise recruitments. 
Volume 9 Issue 9 September 2021

Examinations were taken very seriously. Recruitment by nomination was also transparent and proved its effectiveness. Virtue and talents are the first criteria when it comes to appointing mandarins. The recruitment of mandarins is conducted regularly and in a timely manner to provide truly capable people to work for agencies of the administrative apparatus. That shows the remarkable progress in awareness of how to select mandarins of the Early Le dynasty compared to the previous dynasties.

The Early Le Dynasty achieved its unity of ideology, stability of objectives and resoluteness of measures. Emperors during the Le Dynasty took Confucianism as the guideline to help establish an overall goal of reforming the administrative apparatus, with a view to optimizing the management and administration, and constructing an all-round model of autocratic monarchy. In order to achieve such goals, resolute and concrete measures had to be taken, some of which could be named: The title of TeTuong (grand chancellor) was abolished; only the talented were recruited; those who were not qualified, albeit being noble, would not be recruited; etc. The unity of actions and thoughts was the first and the most decisive factor to secure the success in recruiting talented virtuous people under the Early Le Dynasty.

Reforms in recruiting mandarins under the Early Le Dynasty were synchronized with reforms in administrative apparatus and institutions (most notably under the reign of King Le Thanh Tong). By employing a variety of measures to guarantee the quality of officials, different methods of mandarin selection and recruitment succeeded in attracting talented people without biases and received a lot of support from the people. Therefore, educated and gifted people were given the chance to serve in the court, if they could merit.

In addition, men with royal background were no longer directly appointed to important positions in the court. The standard to be appointed as a mandarin was education background and qualifications, but not any longer social background. Men in the royal family, albeit being rewarded kindly with many privileges, will not be appointed without a qualified educational background. Even mándarins at local levels (from community leader to commune chief) were required to have a definite level of education. Officials and mandarins in districts and regions were required to have participated in Hoi exams. Officials in communes were required to be literate and prove his capability. Illiterate mandarins would be dismissed. Those who exploit their wealth to commit bribery would be sentenced to penal labour, corporal punishments or demotion.

Many progressive reforms in the way of electing mandarins at authority level were made under the Le dynasty, which ended the state of feudalism and separation of power. They also ensured the centralization of authority and consisted in administration from the central to local levels.

The achievements of this ordinance under the Le dynasty resulted in the formation of mandarins attaining both quantity and quality. 'Quan' were standardized in knowledge and titles, while 'Lai'was a crew of professional assistants who were experts in their specialization but also had considerable experience, and contributed responsibly and loyally to the dynasty. The reform in the bureaucrat recruitment method really brought about a synchronous, comprehensive, and profound change in mandarins. In the Le dynasty, most of the scholars who passed the examination joined the administrative apparatus, which showed the success of examination education as well as its importance in the nation's political and social life at that time.

\section{CONCLUSION}

This research presented and analyzed the Le dynasty's ordinance of electing mandarin, including (i) Male hereditary succession (family’s blessings); (ii) Ordinance of nomination; (iii) Imperial Examinations; and (iv) 
Volume 9 Issue 9 September 2021

Some other selection methods.

Bureaucratic recruiting system in the Le dynasty is one of the valuable sources of material for studying the mandarin system. Because mandarins not only play a significant role in organizing the administrative apparatus but also in operating the system itself. Regulations on functions and duties as well as the mandarin system were based on this arrangement of mandarins.

This research is also one of the reference sources when electing personnel in organizations. Organizations, when recruiting staff, need to go through an examination process that includes (i) Setting the ethical criteria and requiring competence of the candidates; (ii) Strictly handling violators in selection activities; (iii) The content of the exam must be practical while promoting historical knowledge; (iv) Organizing the grading process and handling the selection results fairly.

\section{REFERENCES}

1. ConferenceScientific(1997). LeThanh Tong: People and career, University of Social Sciences and Humities, National University of Education, Institute of History, Institute of Philosophy, Institute of State and Law, Judicial Publishing House [Vietnamese].

2. Hoang Phe (2000). Vietnamese Dictionary, Da Nang Publishing House.

3. Le Kim Ngan (1963).The organization of government in Le Thanh Tong dynasty (1460-1497), SaiGon Publishing House.

4. Minh Dat (2006).King of LeThanh Tong and the organizational reform in the post-Le epoch,Journal of Party Building, 1 \& 2; 27-28.

5. Ngo Si Lien and historian of the Le dynasty (1992). Dai Viet history book, 2, 3; Social Sciences Publishing House, Hanoi.

6. PhanHuy Chu (1961). Calendar of tides and charters (Quanchuc chi). I, II; History Publishing House, Hanoi.

7. Pham Van Hao (2008). Handbook of historical words (quanche). Social Sciences Publishing House, Hanoi.

8. Pham TrongBau (1994). Vietnamese education in modern times, Social Sciences Publishing House, Hanoi.

9. National Criminal Code(1991). Juridical Publishing House, Hanoi.

10. Historical Academy of the Nguyen dynasty (1998). Kham Viet History Thong Cuong Section, I, Education Publishing House, Hanoi.

11. Truong HuuQuynh (1992). The reform and construction of the rule of law in the Le Thanh Tong period.Journal of Historical Studies, 6, 37. 